\title{
Effect of hyperoxia on articular tissues in organ culture
}

\author{
R. W. JUBB
}

From the Division of Immunology, Department of Pathology, University of Cambridge, Addenbrooke's Hospital, Cambridge

SUMMARY The effect of hyperoxia on pig articular tissue has been studied in organ culture. Hyperoxia $\left(55 \% \mathrm{O}_{2}\right)$ causes an increased release of hydroxyproline and collagenolytic activity from synovial tissue as compared with control explants in $20 \% \mathrm{O}_{2}$, but neither $55 \%$ nor $95 \% \mathrm{O}_{2}$ has any effect on the breakdown of isolated cartilage during 10 days in culture. When synovium and cartilage are cultured in contact, the breakdown of cartilage collagen is greater in the hyperoxic $\left(55 \% \mathrm{O}_{2}\right)$ group than in the controls $\left(20 \% \mathrm{O}_{2}\right)$, but the breakdown of proteoglycan is not increased. The enhanced collagenolytic action is due to an increase in the direct effect of the synovial tissue on the cartilage matrix. In $20 \% \mathrm{O}_{2}$ the synovium causes the chondrocytes to degrade the cartilage matrix, but this effect is inhibited by $55 \% \mathrm{O}_{2}$.

In osteoarthrosis catabolic enzymes from the chondrocytes are thought to be involved in the destruction of the cartilage (Howell, 1975), and there is increasing evidence that the chondrocytes also play a role in the breakdown of articular cartilage in rheumatoid arthritis (Chaplin, 1971; Muirden et al., 1974). In both these diseases raised levels of lysosomal enzymes have been found in the cartilage (Sapolsky et al., 1973; Muirden et al., 1974), and recently a collagenolytic agent also had been described in osteoarthrotic cartilage (Ehrlich et al., 1977). The factors controlling the behaviour of the chondrocytes in these diseases are not known.

Hyperoxia has been shown to increase the lysosomal enzyme activity of HeLa and chick embryonic cells in cell culture (Allison, 1965). A similar effect was found by Sledge and Dingle in embryonic limb bone rudiments maintained in organ culture in $85 \%$ oxygen; after 8 days there was loss of metachromatic staining in the cartilage matrix associated with increased cathepsin D activity in the medium (Sledge and Dingle, 1965). Loss of proteoglycan from isolated articular cartilage in organ culture has been reported in rabbit knee cartilage cultivated in $90 \%$ oxygen (Brighton et al., 1974) and in human cartilage from the femoral head in $95 \%$ oxygen (Jacoby and Jayson, 1975). At this level of oxygen,

Accepted for publication 5 July 1978

Correspondence to Dr R. W. Jubb, Division of Immunology, Department of Pathology, Laboratories Block, Addenbrooke's Hospital, Hills Road, Cambridge CB2 2QQ. however, three-quarters of the chondrocytes in the human cartilage were dead after 8 days.

Recently Fell and Jubb have studied the destructive effect of synovial tissue on pig articular cartilage in organ culture (Fell and Jubb, 1977). In this system the synovium caused the breakdown of the cartilage both by a direct presumably enzymatic action on the matrix, which required contact between the tissues, and by an indirect action mediated through the chondrocytes via the culture medium, which could operate even when the tissues were widely separated.

Although the level of oxygen is low in rheumatoid synovial cavities (Falchuk et al., 1970), a 3-fold increase in blood flow and oxygen uptake by rheumatoid synovium has been reported (Goetzl et al., 1971).

It was decided to study the effect of hyperoxia on pig articular cartilage and synovium and also on the interaction between the 2 tissues during cultivation in organ culture.

\section{Materials and methods}

\section{TISS UE}

The articular tissues were obtained from the metacarpophalangeal joints of pigs aged 6 to 9 months and weighing 50 to $75 \mathrm{~kg}$, which were routinely killed at a local slaughterhouse.

Cartilage. Samples of cartilage were cut from the distal end of the third and fourth metacarpals. A 
strip was taken from the condylar ridge of each joint, the zone of calcified cartilage and the underlying marrow being avoided. Each strip was cut into 2 equal parts, one half acting as an experimental and the other as a control explant.

Synovial tissue. It was found to be technically impossible to obtain equivalent explants of intact synovium (see Fell and Jubb, 1977). To surmount this difficulty sheets of joint capsule were removed from a number of joints, and the synovial villi and some subsynovial tissue were cut off, finely divided, and the minced tissue from a number of joints was pooled. The pooled synovial mince was washed, well stirred, and measured amounts served as explants.

\section{ORGAN CULTURE}

Medium. The tissues were maintained in $\mathbf{B G J}_{5}$ with $15 \%$ heat-inactivated normal rabbit serum. $\mathbf{B G J}_{5}$ is the chemically defined medium BGJ (Biggers et al., 1961) supplemented with $5 \mathrm{mg}$ sodium acetate and $15 \mathrm{mg}$ ascorbic acid per $100 \mathrm{ml}$. $1.5 \mathrm{ml}$ medium was used for each culture and was changed every $48 \mathrm{~h}$, the old medium being kept for analysis.

Culture system. The culture system was that previously described by Fell and Barratt (1973). Two flat-bottomed glass vessels were enclosed in a Petri dish containing some isotonic saline, which acted as a moist chamber. The explants were placed on a millipore filter $(13 \mathrm{~mm}$ diameter; pore size $8.0 \mu \mathrm{m})$ and supported in the vessels by a table of stainless steel gauze. A measured volume of synovial tissue $(0.025 \mathrm{ml})$ was deposited on the millipore substrate, and a cartilage explant was placed either on the synovium with the articular surface downwards or at a distance from the synovium. Cultures were also made of isolated cartilage or isolated synovial tissue only.

The Petri dishes were stacked in a modified Fildes Mackintosh jar and gassed with one of the following mixtures: $20 \% \mathrm{O}_{2}+5 \% \mathrm{CO}_{2}+75 \% \mathrm{~N}_{2} ; 55 \% \mathrm{O}_{2}+$ $5 \% \mathrm{CO}_{2}+40 \% \mathrm{~N}_{2} ; 95 \% \mathrm{O}_{2}+5 \% \mathrm{CO}_{2}$. The cultures were maintained for 10 days at $38.5 \mathrm{C}$ (body temperature of the pig is $39 \cdot 3 \mathrm{C}$ ).

\section{HISTOLOGY}

After 10 days' cultivation the explants were fixed as previously described (Fell and Barratt, 1973). Serial sections were cut at $6 \mu \mathrm{m}$ and stained with either toluidine blue or the sequence celestine blue, Carazzi's haematoxylin and van Gieson's stain. Toluidine blue stains proteoglycan metachromatically a deep purple, and the van Gieson colours collagen red, with the haematoxylin giving good nuclear detail.

\section{BIOCHEMICAL ASSAYS}

The used culture medium was collected at 2-day? intervals. Each experimental group consisted of $\vec{E}$ explants, and the medium from these cultures was pooled before analysis. It has already been showr that there is good correspondence in the behaviou of paired cartilage explants when they are cultured under identical conditions (Fell and Jubb, 1977) The analytical methods used have been described iff detail elsewhere, and references to them are given in the text.

Proteoglycan. Proteoglycan released into the్ culture medium was estimated by a modificatiow of Whiteman's alcian blue assay (Whiteman, 1973을 Dingle et al., 1975), which measures polyanionico molecules. In view of the interference with the assaw by medium from synovial cultures, the samples were routinely treated with trypsin $(10 \mathrm{mg} / \mathrm{ml}$ before assay (Fell and Jubb, 1977). The standard used for reference was chondroitin sulphate (exe shark's fin, Koch-Light).

Collagen. The amount of hydroxyproline in the medium was determined as an indication of collagere release. It was estimated after acid hydrolysis by the method described by Woessner (Woessner, 1961 Burleigh et al., 1974).

Collagenolytic activity. This was measured by the breakdown of reconstituted collagen fibrils (Wer) and Burleigh, 1974). Purified skin collagen (rat labelled with ${ }^{14} \mathrm{C}$-glycine was used as substrate and clostridial collagenase (Worthington) as a standard the results were expressed as units of bacteriat collagenase. The samples were pretreated with potase sium thiocynate to dissociate enzyme inhibito complexes (Nagai et al., 1975).

\section{Results}

ISOLATED ARTICULAR CARTILAGE

Explants of cartilage were cultured in $20 \%, 55 \%$, o $95 \% \mathrm{O}_{2}$. After 10 days histological examinatio showed no sign of depletion of either proteoglycat or collagen in the 2 hyperoxic groups as compared with their paired controls in $20 \% \mathrm{O}_{2}$ (Table 1, Figf 1). In some of the explants exposed to $95 \%$ pyknotic nuclei were present among the superficiap cells in immediate contact with the atmosphere, buf otherwise the cells of the hyperoxic cartilage appeares viable.

The cumulative release of proteoglycan into th medium was slightly lower in the hyperoxic group, but this was not statistically significant, and there was no release of hydroxyproline. Collagenolyti画 activity was not detected (Table 2).

ISOLATED SYNOVIUM

The synovial explants maintained in $55 \%$ 
appeared macroscopically smaller than the controls in $20 \% \mathrm{O}_{2}$, but no histological difference could be seen. The explants were a jumble of fibrous tissue, synovial lining cells, and fragments of blood vessels. In both groups the cells were viable, with many

Table 1 Effect of oxygen on isolated cartilage in organ culture for 10 days. Analysis of histology*

\begin{tabular}{|c|c|c|c|c|c|c|c|}
\hline \multirow{2}{*}{$\begin{array}{l}\text { No. of } \\
\text { explants }\end{array}$} & \multirow{2}{*}{$\begin{array}{l}\% \\
\text { oxygen }\end{array}$} & \multicolumn{6}{|c|}{ Loss of proteoglycan (toluidine blue) } \\
\hline & & +++ & +++ & ++ & + & \pm & 0 \\
\hline $\begin{array}{r}12 \\
12 \\
9\end{array}$ & $\begin{array}{l}20 \\
55 \\
95\end{array}$ & & & & 2 & $\begin{array}{l}4 \\
3 \\
3\end{array}$ & $\begin{array}{l}6 \\
9 \\
6\end{array}$ \\
\hline
\end{tabular}

*The degree of depletion of the proteoglycan and collagen of the matrix, as shown by their staining reactions, is expressed by the + signs. Proteoglycan $++++=$ total absence of metachromasia; $\mathbf{0}=$ no effect. Collagen $++++=$ complete disappearance of all intercellular material; $\mathbf{0}=$ no effect. Intermediate changes in both components are represented by,,,++++++ \pm . The number of explants in each group is shown. (In the legends for the photographs, each specimen illustrated is graded according to the above scale.) invading the millipore substrate, and mitotic figures were common.

Analysis of the used medium (Table 2) showed significantly more proteoglycan and hydroxyproline in the hyperoxic than in the control cultures. Only a small amount of material precipitable with alcian blue was released from either set, and its exact nature has not been determined. Latent collagenolytic activity was present in the medium of both hyperoxic and control cultures; it was $36 \%$ higher in the hyperoxic group.

\section{CARTILAGE IN CONTACT WITH SYNOVIUM}

After 10 days' cultivation in contact with synovial tissue metachromasia was often completely absent in both the hyperoxic $\left(55 \% \mathrm{O}_{2}\right)$ and the control explants (Fig. 2, Table 3). but breakdown of collagen was greater in the hyperoxic cartilage (Table 3). In sections stained with van Gieson's stain it was seen that the degradation of the collagen began at the
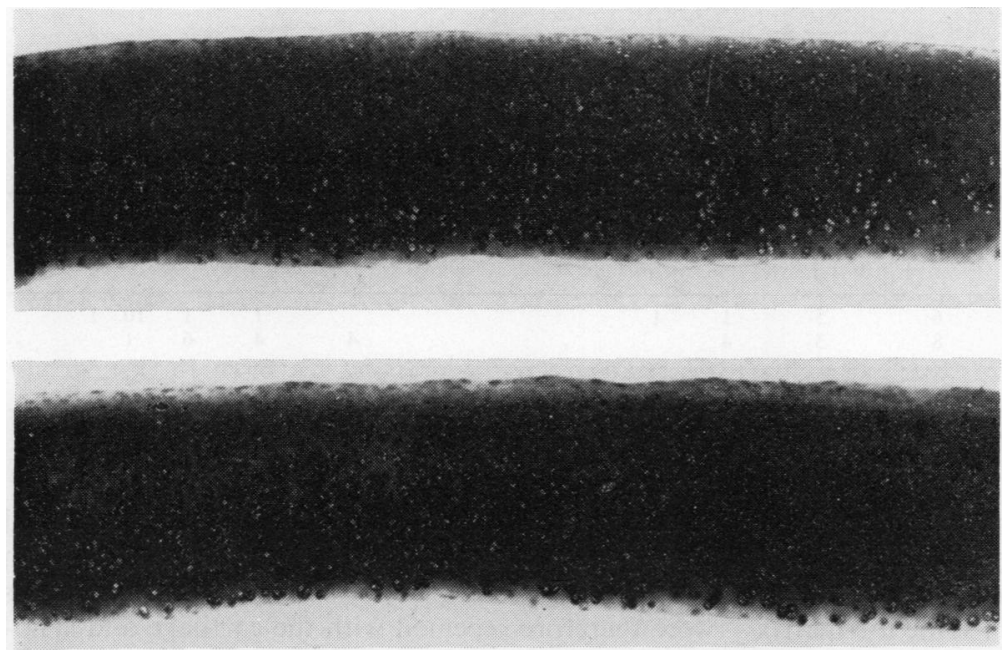

Fig. 1 (Upper) Section of isolated cartilage maintained in organ culture with $55 \% O$, for 10 days. No loss of metachromasia (grade 0 , see Table 1). Toluidine blue, $\times 35$. (Lower) Section of paired control cartilage maintained in $20 \%$ oxygen for 10 days. No loss of metachromasia (grade 0). Toluidine blue, $\times 35$

Table 2 Analysis of culture medium. Each value is the mean from at least 5 separate experiments

\begin{tabular}{|c|c|c|c|c|c|c|c|c|c|}
\hline & \multicolumn{3}{|c|}{ Cumulative release of proteoglycan } & \multicolumn{3}{|c|}{ Cumulative release of hydroxyproline } & \multicolumn{3}{|c|}{$\begin{array}{l}\text { Cumulative release of collagenolytic } \\
\text { activity }\end{array}$} \\
\hline & $\begin{array}{l}20 \% \text { oxygen } \\
\mu \mathrm{g} / \mathrm{ml}\end{array}$ & *55\% oxygen & $\begin{array}{l}+P \\
\text { value }\end{array}$ & $\begin{array}{l}20 \% \text { oxygen } \\
\mu \mathrm{g} / \mathrm{ml}\end{array}$ & $55 \%$ oxygen & $P$ value & $\begin{array}{l}20 \% \text { oxygen } \\
\text { units } / \mathrm{ml}\end{array}$ & $55 \%$ oxygen & $P$ value \\
\hline $\begin{array}{l}\text { Isolated cartilage } \\
\text { Isolated }\end{array}$ & $86(13)^{* *}$ & $-14 \%(12)$ & NS & 0 & 0 & & 0 & 0 & \\
\hline $\begin{array}{l}\text { synovium } \\
\text { Cartilage }+ \\
\text { synovium in }\end{array}$ & $23(8)$ & $+50 \%(34)$ & $<0.05$ & $50(3)$ & $+45 \%(13)$ & $<0.005$ & $3 \cdot 17(3 \cdot 5)$ & $+36 \%$ (19) & $<0.01$ \\
\hline $\begin{array}{l}\text { contact } \\
\text { Cartilage }+ \\
\text { synovium } \\
\text { separated }\end{array}$ & $208(102)$ & $-20 \%(19)$ & NS & $56(16)$ & $+62 \%(24)$ & $<0.001$ & $1 \cdot 33(0 \cdot 75)$ & $+58 \%(38)$ & $<0.005$ \\
\hline
\end{tabular}

*Results in $55 \%$ oxygen expressed as a percentage of their paired controls in $20 \%$ oxygen. $†$ Paired explants analysed by paired $t$ test. NS not significant. ${ }^{* *}$ Standard deviation. 

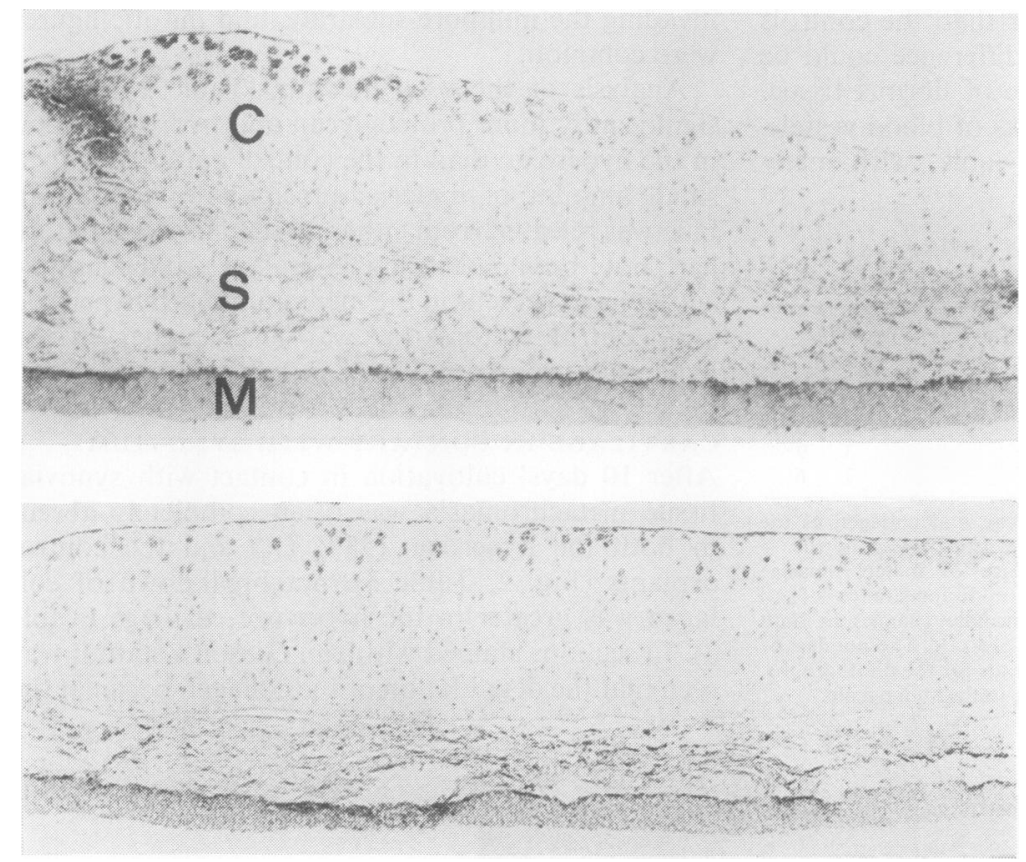

Fig. 2(Upper) Section of cartilage and synovium in contact after 10 days in $55 \% \mathrm{O}_{2}$. Complete loss of metachromasia (grade ++++ ). $C=$ cartilage,$S=$ synovium, $M=\mathscr{C}$ millipore. Toluidine blue, $\times 35$. (Lower) Section of paired control? explant in $20 \% \mathrm{O}_{2}$ for 10 days. Complete loss of metachromasia (grade ++++ ). Toluidine blue, $\times 35$

Table 3 Effect of oxygen on cartilage in contact with synovium in organ culture for 10 days. Analysis of histology*

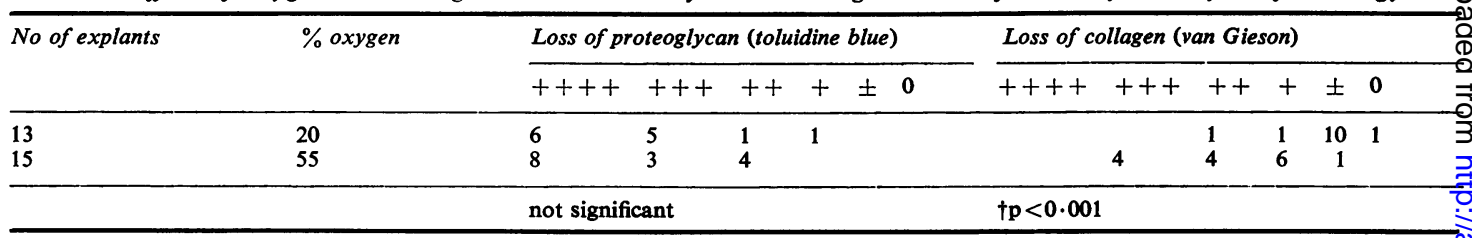

*The degree of depletion is described in Table 1. †Paired explants analysed by paired $t$ test.

margin of the articular zone, the surface of which was in contact with the synovial tissue. There was considerable variation in the degree of breakdown in different pairs of explants, and in some the matrix had almost disappeared in the specimens cultured in high oxygen (Fig. 3).

The biochemical findings confirmed the histological observations. There was little difference either in the amount of proteoglycan liberated by the 2 groups after 10 days or in the pattern of its release (Fig. 4). In the hyperoxic cultures, however, the collagenolytic activity of the used medium was about $50 \%$ higher than that of the controls and about $60 \%$ more hydroxyproline was released (Table 2).

\section{CARTILAGE SEPARATED FROM SYNOVIUM}

From the above results it was not clear whether the hyperoxia accelerated the breakdown of cartilage in contact with synovium by enhancing the direct enzymatic action of the synovium on the cartilage matrix, by increasing its indirect effect mediateç through the chondrocytes, or by stimulating bot? processes (Fell and Jubb, 1977). The experiments were therefore repeated with the cartilage and syno vium grown on the same Millipore but at a distance from each other; this system would exclude the direc至 action of the synovium, for which contact betweerf the 2 tissues is required.

Histological examination of the cartilage explant after 10 days' incubation under these conditions so $^{\circ}$ showed that, far from increasing the indirect action of the synovium, the hyperoxia actually diminishe the loss of both metachromatic material and colp lagen from the matrix (Fig. 5, Table 4). The cartilage was placed on the millipore with the articular surface upwards; in the controls $\left(20 \% \mathrm{O}_{2}\right)$ the areat immediately above the millipore, which included the cells of the columnar zone, showed depletion of the matrix and the transformation of the chrondro? cytes into basophilic cells of irregular shape, ofters 

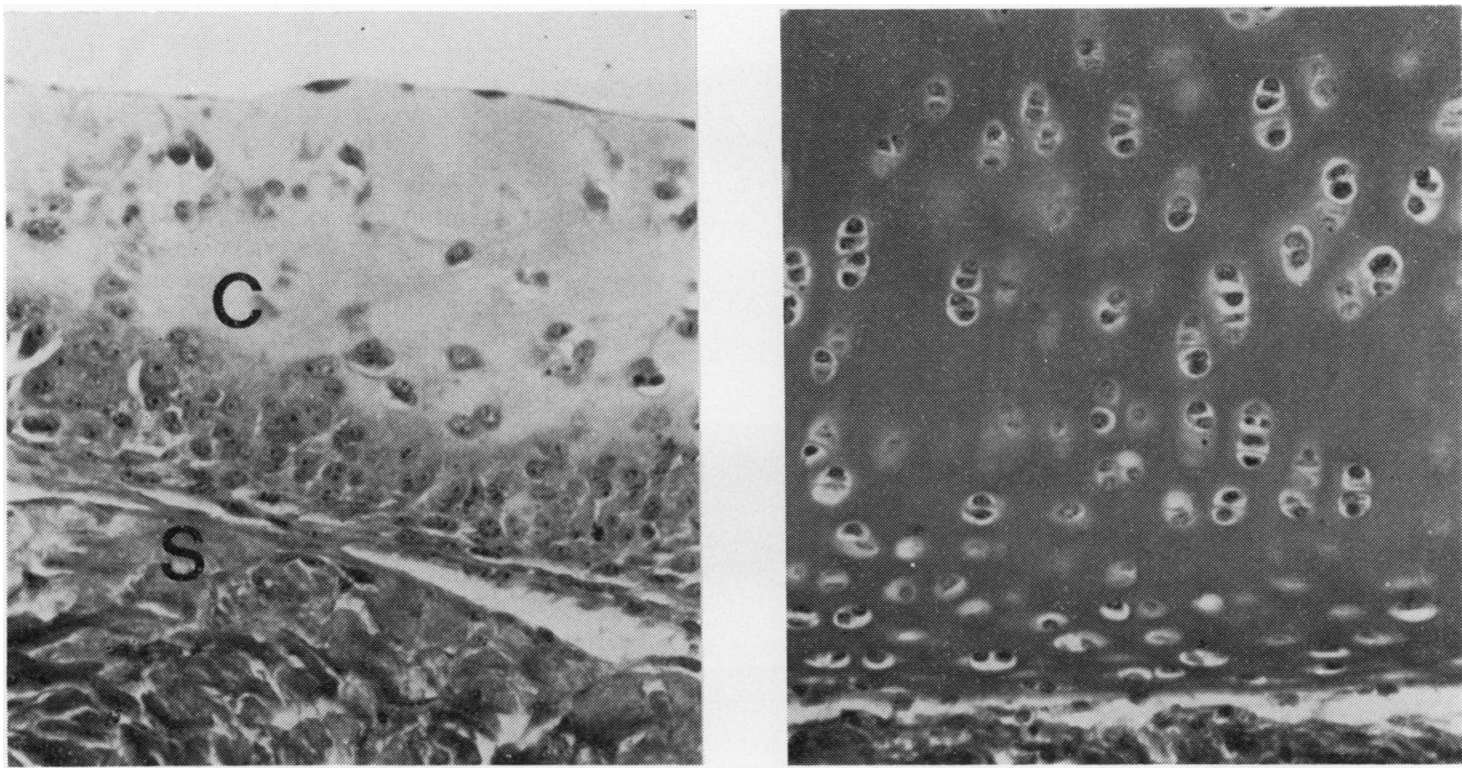

Fig. 3 (Left) High power of same explant as in Fig. 2 (upper). Cartilage in contact with synovium after 10 days in $55 \% \mathrm{O}_{2}$. Loss of intercellular collagen from the cartilage with viable chondrocytes. $C=$ cartilage, $S=s y n o v i u m$. van Gieson, $\times 250$. (Right) High power of paired explant after 10 days in $20 \% \mathrm{O}_{2}$. Collagenous component of cartilage matrix intact. van Gieson, $\times 250$

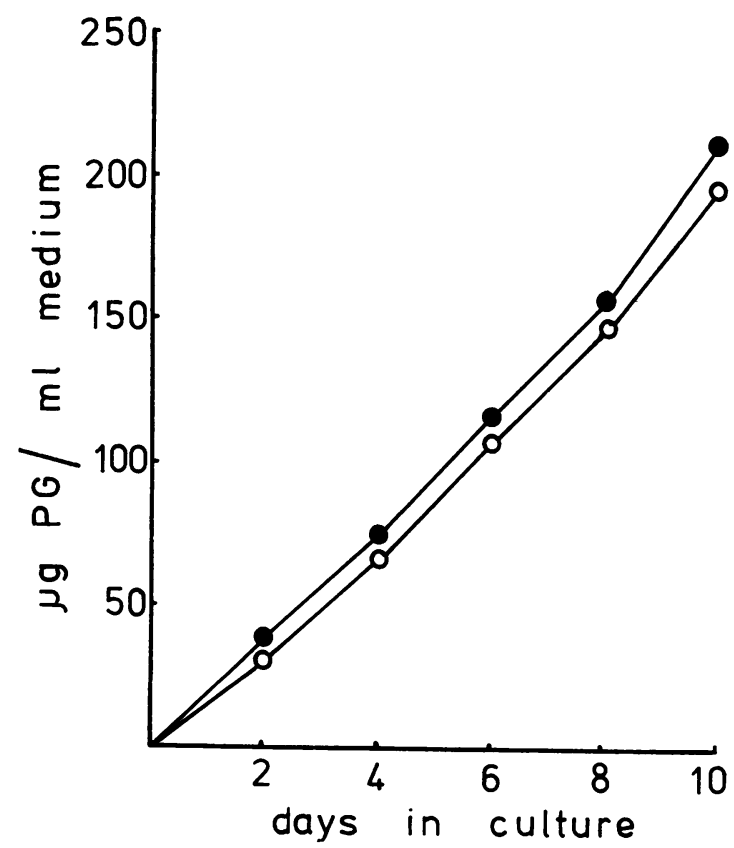

Fig. 4 Cumulative release of proteoglycan $(P G)$ from explants of cartilage in contact with synovium. $=$ explants maintained in $55 \% \mathrm{O}_{2} . \mathrm{O}=$ explants maintained in $20 \% \mathrm{O}_{2}$. Graphs represent the mean values from four paired explants in active mitosis (Fig. 6). These changes, though not entirely suppressed, were less obvious in the cultures exposed to $55 \% \mathrm{O}_{2}$.

Biochemical assay of the used medium showed that the hyperoxic tissues released less proteoglycan into the medium than the controls in $20 \%$ oxygen (Table 2). Virtually all of this material is derived from the cartilage, as the synovium liberates very little.

The hydroxyproline in the used medium, which reflects the breakdown of collagen comes from both the cartilage and the synovium, and in these experiments it was only $24 \%$ above that in the used control medium, in contrast to a difference of $60 \%$ when the 2 tissues were in contact. The latent collagenolytic activity, which is produced entirely by the synovial explant, was about $50 \%$ higher in the hyperoxic group.

These results imply that the increased breakdown of cartilage matrix induced by hyperoxia $(55 \%)$ when the cartilage is in contact with the synovial tissue is due to an enhancement of the direct enzymatic action of the synovium on the matrix. The release of proteoglycan is unaffected, and the increased destruction of the matrix is due to breakdown of collagen,which correlates with an increased release of collagenolytic activity from the synovium. This effect is seen despite inhibition of the collagenolytic action of the chondrocytes. 

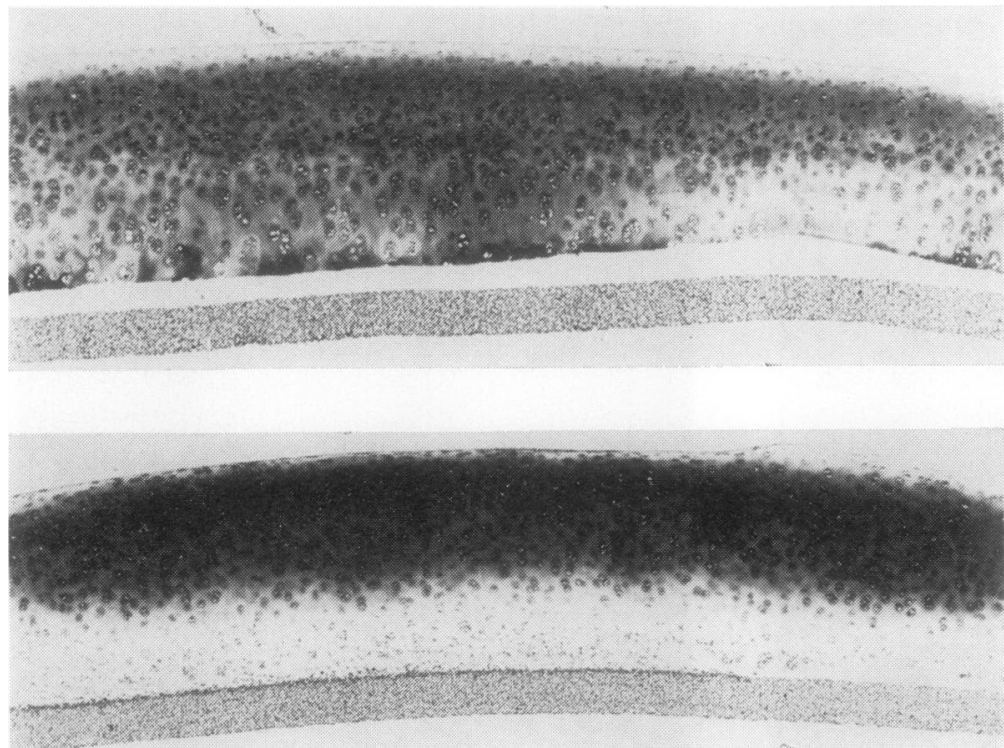

Fig. 5 (Upper) Section of cartilage maintained at a distance from synovial tissue in organ culture. Ten days' culture in $55 \% \mathrm{O}_{2}$. Patchy loss of metachromasia (grade +). Toluidine blue, $\times 35$. (Lower) Section of paired control explant maintained in $20 \% \mathrm{O}_{2}$ for 10 days. Zone of loss of metachromasia above millipore $($ grade ++$)$. Toluidine blue, $\times 35$

Table 4 Effect of oxygen on cartilage separated from synovium in organ culture for 10 days. Analysis of histology*

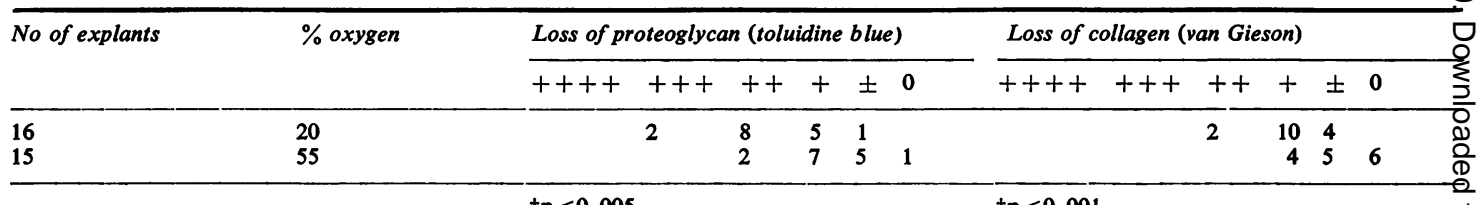

*The degree of depletion is described in Table 1. †Paired explants analysed by paired $t$ test.
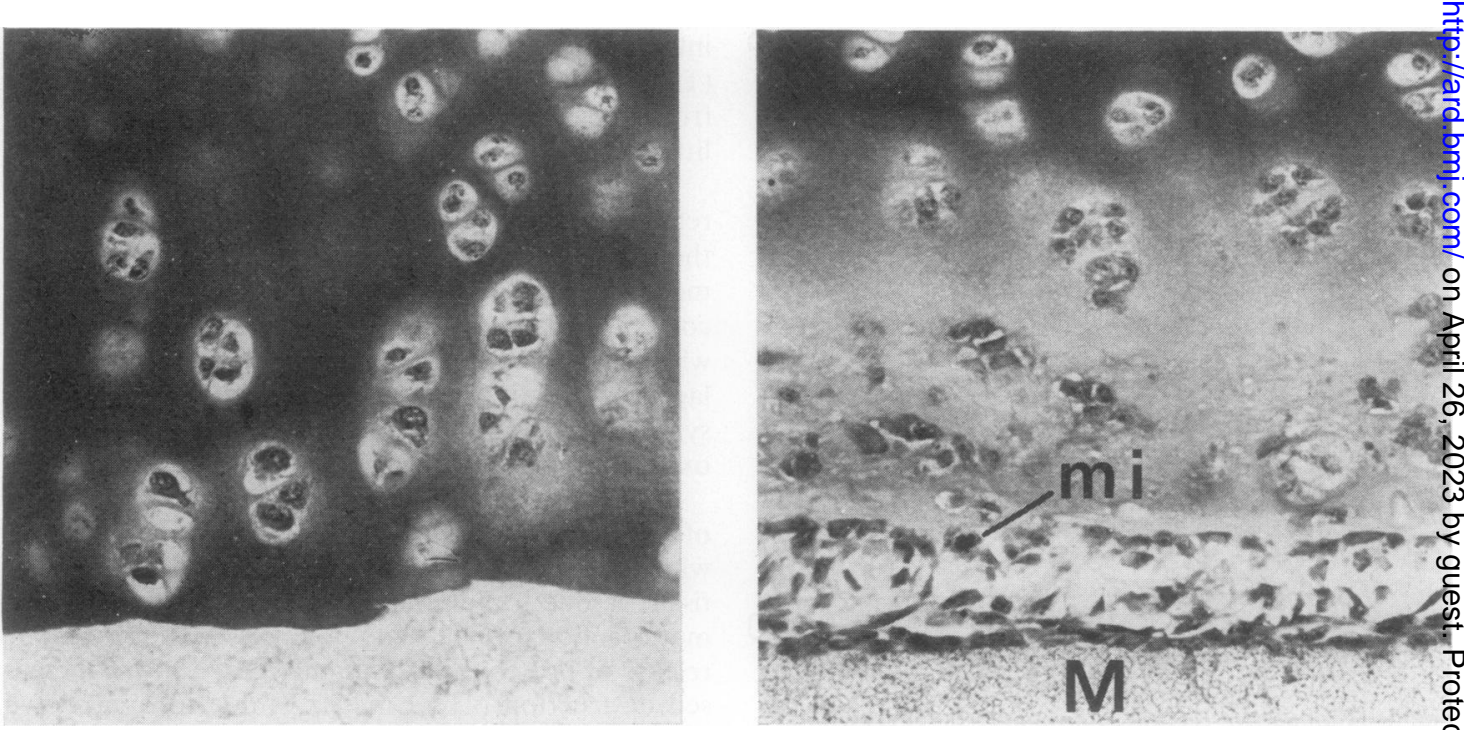

Fig. 6 (Left) High power of same explant as in Fig. 5. (Upper) Cartilage at a distance from synovium, after 10 days culture in $55 \% \mathrm{O}_{2}$. Minimal depletion of collagen. van Gieson, $\times 250$. (Right) High power of paired explant after 10 days in $20 \% \mathrm{O}_{2}$. Loss of intercellular collagen with proliferation of chondrocytes. $M=$ millipore, mi=mitosis. Van Gieson, $\times 250$ 


\section{Discussion}

In the organ cultures of isolated articular cartilage from pig hyperoxia (55\% and $95 \%$ oxygen) neither caused loss of metachromasia nor increased the amount of proteoglycan shed into the medium; indeed slightly less was released than by the controls in $20 \%$ oxygen. There was no evidence of loss of collagen. Jacoby noted some loss of proteoglycan from adult human articular cartilage after 8 days' cultivation at an oxygen tension of $95 \%$, but more than three-quarters of the nuclei were pyknotic, which raises the possibility that the degradation of proteoglycan might have been due to the liberation of autolytic enzymes from these necrotic cells (Jacoby and Jayson, 1975).

In the present experiments isolated synovial tissue released a collagenolytic agent into the medium. The synthesis of collagenase by synovial tissue in vitro has been reported by others (Evanson et al., 1967; Werb and Reynolds, 1975), and raised levels have been found in cultures of rheumatoid synovium (Harris et al., 1969). The exact nature of the collagenolytic agent produced by synovial mince in culture is not known, nor are the factors that control its release understood. Its synthesis may be a response to the trauma inflicted on the tissue during preparation and possibly to the abnormal environment to which it is exposed in an organ culture. Although some was found in the medium at normal $(20 \%)$ oxygen tension, the amount was increased by hyperoxia. Williams (1973) found that the optimum concentrations of oxygen for maintaining human synovium in organ culture were between $20 \%$ and $50 \%$. Probably the tissue, which has an aerobic metabolism (Bywaters, 1937), is physiologically more active at the higher level.

In earlier work Fell and Jubb (1977) found that, when cartilage was cultivated in contact with synovium in $20 \%$ oxygen, its matrix was severely depleted though the chondrocytes survived. This was shown to be caused by 2 mechanisms: a direct, probably enzymatic effect of the synovial cells on the matrix and an indirect action mediated through the chondrocytes via the culture medium. In the present study hyperoxia greatly enhanced the breakdown of cartilage in contact with synovium, apparently by stimulating the direct action of the synovium on the matrix. When the direct effect was eliminated by cultivating the cartilage at a distance from the synovial explant, the partial breakdown of the matrix seen at $20 \%$ oxygen was reduced by exposure to $55 \%$ oxygen.

Thus the indirect action of the synovial cells on the matrix, in contrast to their direct action, was inhibited by the raised oxygen. It is possible that either the hyperoxia prevented the synovial tissue from producing the changes in the culture medium that stimulate the chondrocytes to destroy their matrix, or that it inhibited the chondrocytes from reacting to the stimulus. The latter seems the more probable explanation. Unlike the synovium, cartilage has a largely anaerobic metabolism (Bywaters, 1937). That hyperoxia has an inhibitory effect on at least one synthetic activity of the chondrocytes has been shown by Lemperg et al. (1975), who found that exposure to $50 \%$ oxygen reduced the uptake of ${ }^{35} \mathrm{SO}_{4}$ into calf articular cartilage in organ culture. It may well be that the synthesis of the enzymes responsible for the degradation of the matrix is similarly inhibited in living cartilage.

Sledge and Dingle (1965) cultivated the cartilaginous limb-bone rudiments of the chick in an atmosphere of $85 \%$ oxygen and found that the matrix was severely depleted of proteoglycan. In the present experiments, however, hyperoxia failed to cause the breakdown of isolated articular cartilage. This apparent discrepancy between the two sets of results may be attributable to the fact that the limb-bone rudiments were enclosed in a sheath of connective tissue. It may well be that Sledge and Dingle's experimental system corresponded to the afronted explants of synovium and articular cartilage in which hyperoxia caused severe breakdown, rather than to the explants of isolated articular cartilage devoid of soft connective tissue. Alternatively, the chondrocytes of embryonic limb bones may respond differently to hyperoxia in organ culture.

It remains to be seen whether the action of hyperoxia on synovial tissue and cartilage in organ culture is related to the pathogenesis of inflammatory arthritis. In culture raised levels of synovial collagenolytic activity may be asssociated with an increased destruction of cartilage collagen provided the tissues are in contact. In rheumatoid erosion of cartilage matrix the synovium is known to synthesise collagenase (Evanson et al., 1967), and during episodes of acute inflammation it becomes hyperaemic, with a consequent increase in the availability of oxygen. Whether this accelerates the destruction of the articular cartilage is not known.

The author is greatly indebted to Dame Honor Fell, FRS, for valuable advice and criticism and for reading the manuscript. Dr J. T. Dingle, Strangeways Research Laboratory, kindly provided the ${ }^{14} \mathrm{C}$-labelled collagen. Mr R. E. Green prepared the photographs. The pigs' trotters were supplied free of charge by R. E. Garnham and Sons Ltd. I thank Professor R. R. A. Coombs, FRS, for his encouragement and for providing laboratory accommodation in his department. Finally I gratefully acknowledge the Nuffield Rheumatism Committee for a clinical research fellowship. 


\section{References}

Allison, A. C. (1965). Role of lysosomes in oxygen toxicity. Nature, 205, 140-143.

Biggers, J. D., Gwatkin, R. B. L., and Heyner, S. (1961). Growth of embryonic avian and mammalian tibiae on a relatively simple chemically defined medium. Journal of Experimental Cell Research, 25, 45-58.

Brighton, C. T., Lane, J. M., and Koh, J. K. (1974). In vitro rabbit articular cartilage organ model. II. ${ }^{35} \mathrm{~S}$ incorporation in various oxygen tensions. Arthritis and Rheumatism, 17, 245-252.

Burleigh, M. C., Barrett, A. J., and Lazarus, G. S. (1974). Cathepsin B1: a lysosomal enzyme that degrades native collagen. Biochemical Journal, 137, 387-398.

Bywaters, E. G. L. (1937). The metabolism of joint tissues. Journal of Pathology and Bacteriology, 44, 247-268.

Chaplin, D. M. (1971). The pattern of bone and cartilage damage in the rheumatoid knee. Journal of Bone and Joint Surgery, 53B, 711-717.

Dingle, J. T., Horsfield, P., Fell, H. B., and Barratt, M. E. J. (1975). Breakdown of proteoglycan and collagen induced in pig articular cartilage in organ culture. Annals of the Rheumatic Diseases, 34, 303-311.

Ehrlich, M. G., Mankin, H. J., Jones, H., Wright, R., Crispin, C., and Vigliani, G. (1977). Collagenase and collagenase inhibitors in osteoarthritic and normal human cartilage. Journal of Clinical Investigation, 59, 226-233.

Evanson, J. M., Jeffrey, J. J., and Krane, S. M. (1967). Human collagenase: identification and characterisation of an enzyme from rheumatoid synovium in culture. Science, 158, 499-502.

Falchuk, K. H., Goetzl, E. J., and Kulka, J. P. (1970). Respiratory gases of synovial fluids. An approach to synovial tissue circulatory-metabolic imbalance in rheumatoid arthritis. American Journal of Medicine, 49, 223-231.

Fell, H. B., and Barratt, M. E. J. (1973). The role of soft connective tissue in the breakdown of pig articular cartilage cultivated in the presence of complement sufficient antiserum to pig erythrocytes. I. Histological changes. International Archives of Allergy and Applied Immunology, 44, 441-468.

Fell, H. B., and Jubb, R. W. (1977). The effect of synovial tissue on the breakdown of articular cartilage in organ culture. Arthritis and Rheumatism, 20, 1359-1371.

Goetzl, E. J., Falchuk, K. H., Zeiger, L. S., Sullivan, A. L., Herbert, C. L., Adams, J. P., and Decker, J. L. (1971).
A physiological approach to the assessment of disease activity in rheumatoid arthritis. Journal of Clinical Invest $i$ gation, 50, 1167-1180

Harris, E. D. Jr., Cohen, G. L., and Krane, S. M. (1969) Synovial collagenase: its presence in culture from joine disease of diverse aetiology. Arthritis and Rheumatism 12, 92-102.

Howell, D. S. (1975). Degradative enzymes in osteoarthritiō内 human articular cartilage. Arthritis and Rheumatism, 18 167-177.

Jacoby, R. K., and Jayson, M. I. V. (1975). Organ culture of adult human articular cartilage. I. The effect of hyperoxia on synthesis of glycosaminoglycan. Journal of Rheumato$\log y, 2,270-279$.

Lemperg, R. K., Bergenholtz, A., and Smith, T. W. D. (1975) Calf articular cartilage in organ culture in a chemically defined medium. 2. Concentration of glycosaminoglycan and ${ }^{35} \mathrm{~S}$ sulphate incorporation at different oxygen ten- $\infty$ sions. In Vitro, 11, 291-301.

Muirden, K. D., Deutschmann, P., and Phillips, M. (1974) N Articular cartilage in rheumatoid arthritis: Ultrastructureco and enzymology. Journal of Rheumatology, 1, 24-33.

Nagai, Y., Hori, H., Kawamoto, T., and Komya, M. (1975). Regulative mechanism of co!lagenase activity in vitro and vivo. In Dynamics of Connective Tissue Macromolecules, p. 171. Edited by P. M. C. Burleigh and A. R. Poole.त्( North Holland Amsterdam American Elsevier: New York.

Sapolsky, A. I., Altman, R. D., and Howell, D. S. (1973). Cathepsin D activity in normal and osteoarthrotic humanco cartilage. Federation Proceedings, 32, 1489-1493.

Sledge, C. B., and Dingle, J. T. (1965). Activation of 1yso-o somes by oxygen. Nature, 205, 140-143.

Werb, Z., and Burleigh, M. C. (1974). A specific collagenase from rabbit fibroblasts in monolayer culture. Biochemicalo Journal, 137, 373-385.

Werb, Z., and Reynolds, J. J. (1975). Purification and properties of a specific collagenase from rabbit synovial fibroblasts. Biochemical Journal, 151, 645-653.

Whiteman, P. (1973). The quantitative measurement of alcian blue-glycosaminoglycan complexes. Biochemical Journal, 131, 343-350.

Williams, P. (1973). Human synovium in organ culture. In Tissue Culture in Medical Research, p. 16. Heinemann: London.

Woessner, J. F. (1961). The determination of hydroxyproline in tissue and protein samples containing small proportionsiof this imino acid. Archives of Biochemistry and Bio-윽 physics 93, 440-447. 